\title{
Identifying Self-Management Support Needs for Pregnant Women With Opioid Misuse in Online Health Communities: Mixed Methods Analysis of Web Posts
}

Ou Stella Liang ${ }^{1}$, MHA; Yunan Chen ${ }^{2}, \mathrm{PhD}$; David S Bennett ${ }^{3}, \mathrm{PhD}$; Christopher C Yang ${ }^{1}, \mathrm{PhD}$

${ }^{1}$ College of Computing and Informatics, Drexel University, Philadelphia, PA, United States

${ }^{2}$ Donald Bren School of Information and Computer Sciences, University of California, Irvine, Irvine, CA, United States

${ }^{3}$ Department of Psychiatry, College of Medicine, Drexel University, Philadelphia, PA, United States

Corresponding Author:

Christopher C Yang, PhD

College of Computing and Informatics

Drexel University

3675 Market St

Philadelphia, PA

United States

Phone: 12158951631

Email: chris.yang@drexel.edu

\section{Abstract}

Background: The current opioid crisis in the United States impacts broad population groups, including pregnant women. Opioid use during pregnancy can affect the health and wellness of both mothers and their infants. Understanding women's efforts to self-manage opioid use or misuse in pregnancy is needed to identify intervention points for improving maternal outcomes.

Objective: This study aims to identify the characteristics of women in an online health community (OHC) with opioid use or misuse during pregnancy and the self-management support needs of these mothers.

Methods: A total of 200 web posts by pregnant women with opioid use participating in an OHC were double coded. Concepts and their thematic connections were identified through an inductive process until theoretical saturation was reached. Statistical tests were performed to identify patterns.

Results: The majority of pregnant women (150/200, 75.0\%) in the OHC exhibited signs of misuse, and 62.5\% (125/200) of the participants were either contemplating or pursuing dosage reduction. Self-managed withdrawal was more common $(P<.001)$ than professional treatment among the population. A total of 5 themes of self-management support needs were identified as women sought information about the potential adverse effects of gestational opioid use, protocols for self-managed withdrawal, pain management safety during pregnancy, hospital policies and legal procedures related to child protection, and strategies for navigating offline support systems. In addition, 58.5\% (117/200) of the pregnant women expressed negative emotions, of whom only $10.2 \%$ $(12 / 117)$ sought to address their emotional needs with the help of the OHC.

Conclusions: OHCs provide vital self-management support for pregnant women with opioid use or misuse. Women pursuing self-managed dosage reduction are prone to misinformation and repeated relapses, which can result in extreme measures to avoid testing positive for drug use at labor. The study findings provide evidence for public policy considerations, including universal screening of substance use for pregnant women, emphasis on treatment rather than legal punishment, and further expansion of the Drug Addiction Treatment Act waiver training program. The improvement of web-based platforms that can organize geo-relevant information, dispense clinically validated withdrawal schedules, and offer structured peer support is envisioned for harm reduction among pregnant women who opt for self-management of opioid misuse.

(J Med Internet Res 2021;23(2):e18296) doi: 10.2196/18296

\section{KEYWORDS}

self-management; online health community; opioid use disorder; pregnancy 


\section{Introduction}

\section{Background}

I literally feel like this is the end. Like there is no way out. ...I don't want the heroin to harm the baby and I don't want withdrawals to harm the baby. And I don't have the money... [P1311]

This is a quote from a pregnant woman in an online health community (OHC) who shared her dire circumstances. She is one of an estimated 21,000 pregnant women who reported misuse of opioids in the past month in the United States [1]. In a recent Centers for Disease Control and Prevention study, 6.6\% of women reported using prescription opioids during pregnancy, among whom $21.2 \%$ reported misuse (ie, illicit use or nonmedical use of prescription opioids) [2]. Pregnant women who misuse opioids face obstetric complications, and their infants are at risk of developing neonatal abstinence syndrome (NAS), which can impede neonatal growth and increase the risk of other physical and developmental problems [3].

\section{Study Aims}

Opioid use during pregnancy is heavily stigmatized and may be legally prosecuted in many states [4,5]. Therefore, we hypothesize that women may choose to self-manage their drug use without the assistance of a health care provider, and as a result, little is known from clinical data about their health challenges and behaviors. To better understand their experiences, we examine data from an $\mathrm{OHC}$, where women seek help, in part, because of the community's anonymity. This study aims to identify (1) the characteristics of women in a public OHC who self-manage their opioid use during pregnancy and (2) their self-management support needs by qualitatively analyzing personal narratives posted in the community. In doing so, we hope to identify intervention points at the policy, organizational, and technology levels that can support the unique needs of this population and achieve harm reduction.

Next, we will briefly review the related literature on the treatment of opioid misuse during pregnancy, barriers to care for pregnant women with opioid use, self-management support, and OHCs.

\section{Treatment for Opioid Misuse During Pregnancy}

Research on the best clinical practice for managing opioid use disorder (OUD) in pregnancy has significantly advanced in the past two decades [6-8]. The American College of Obstetricians and Gynecologists recommends medication-assisted treatment (MAT) over medically supervised withdrawal (because of high relapse rates associated with withdrawal), modified prenatal care elements for OUD-related health needs, and postpartum psychosocial support services [9]. Among MAT medications, buprenorphine may result in better neonatal outcomes than methadone, including higher birth weights and lower treatment times for NAS [10]. Definitions related to OUD and treatment can be found in Multimedia Appendix 1 [8-14].

\section{Barriers to Care for Pregnant Women With Opioid Use}

Survey studies and interview-based qualitative analyses have provided a contextual understanding of the barriers to care, including prenatal care and substance use treatment, encountered by pregnant women with opioid misuse. They are often of low socioeconomic status and experience significant obstacles such as lack of insurance coverage and transportation to access prenatal care, with their opioid use making it more difficult to resolve these barriers $[15,16]$. With regard to seeking substance use treatment in pregnancy, fear of losing child custody and concerns about being stigmatized are cited by pregnant women as barriers [17].

\section{Self-Management Support}

Health agencies in the United States and across the world have recently recognized the importance of facilitating patients' self-efficacy in managing chronic conditions. Self-management support focuses on empowering individuals to take active steps in managing their own chronic conditions by providing the necessary skills and confidence via interventions such as physical activities, education, and peer support [18-20]. Studies have demonstrated the effectiveness of self-management support programs, to an extent, for managing long-term conditions such as diabetes, heart failure, dementia, and Parkinson disease [21-27].

There is evidence that self-management support interventions alongside standard care can be effective for severe mental health problems [28,29], although specific interventions for substance use disorders (SUD) have not been designed or studied [30]. A search on self-management support for substance use disorder on PubMed yielded few relevant results at the time of writing (November 2020). Brown and Altice [31] studied themes related to self-management of MAT medications and found that online participants discussed personal experience and strategies of using unprescribed medication, distrust with health care providers, and desire to recover. Schaub et al [32] demonstrated the effectiveness of a web-based self-help intervention for participants with problematic cannabis use if it can be supplemented by brief chat counseling.

\section{OHCs}

Multiple studies point to the utility of web-based interventions in the negotiation of self-management work [27,29,33-35]. A meta-analysis found 4 mechanisms of self-management support in online groups: collective knowledge and identity building through lived experience, social support through readily accessible gifting relationships, sociability beyond illness, and online disinhibition [35]. Here, we view OHCs in their broadest sense: they are self-organizing web-based interest groups voluntarily joined by patients, caretakers, and sometimes health professionals with a shared interest in similar health conditions. OHCs can exist in dedicated forums, such as PatientsLikeMe [36] and BabyCenter [37]; in mobile health apps, such as fertility and dietary tracking apps; or on general-purpose social media platforms, such as Facebook and Reddit. They can be created and governed by health care organizations, technology companies, or patient advocacy groups. 
The majority (61\%) of US adults use the internet to find health information [38]. Health consumers turn to OHCs, where participants exercise collective sense making to process competing online viewpoints $[39,40]$, to gain experiential expertise from peers that their physicians may not provide [41-44], and to formulate actionable insights for health management [44-46]. Pregnant women seek peer support from OHCs because of constrained access to health care, dissatisfaction with care received, limited offline support, and the unavailability of information from other venues [47]. In addition to information dissemination, several studies point to OHC's utility in enhancing human connection [48-51] and in helping participants overcome stigma [49,52]. Social ties formed in online groups provide space for self-management work that can improve the experience of participants with long-term illnesses [35]. As such, OHCs provide a suitable setting by which we can obtain an initial understanding of people's experiences in sensitive and stigmatized situations, capturing not only their circumstances but also their emotional states $[42,45,53]$. The disadvantages of OHCs, however, include their lack of quality assurance on the consumer health information provided [54], a lack of recognized credibility from health care providers [55], and possible reinforcement of negative behaviors among people in the same network [56].

\section{Methods}

\section{Data Source}

We analyzed participant-generated content from an $\mathrm{OHC}$ (name omitted for the protection of user privacy) that has a long-standing history and active user participation. Compared with other social media platforms, the $\mathrm{OHC}(1)$ is anonymous, allowing for discussion of stigmatized and sensitive health topics; (2) does not have length limits, thereby providing space for relatively detailed accounts of personal experiences; (3) has a wide range of coverage in health condition topics, including pregnancy, substance use, and pain management, so that participants are not constrained to discuss only one aspect of their health given the complex nature of gestational opioid use; and (4) has a long history that allows us to study the activities of OHC participants at the beginning of the millennium when reports of overdoses from prescribed opioids began to rise sharply [57].

\section{Ethics and Privacy Protection}

OHC content is considered public and exempt by institutional review boards as publicly available social media data per the Code of Federal Regulations (CFR) Title 45 Part 46.101 Paragraph (b) Categories of exempt human subject research (4) [58]. We took precautions in handling the OHC data because of its sensitive nature $[59,60]$. The data set was deidentified by removing users' screen names and assigning a randomly generated identifier number independent of the OHC. In reporting the findings, quoted sentences were removed from potentially sensitive personal information (eg, state of residence), misspellings were corrected to help mask linguistic identity, and recounts of events were paraphrased.

\section{Data Collection}

We queried the said OHC for posts made from 2000 to 2019 that contain a pregnancy concept equivalent and at least one OUD-related drug name. A set of pregnancy concept equivalents, namely, "pregnant, pregnancy, expecting, baby, infant, fetus, preggers, and preggy", was iteratively developed by incorporating common expressions in sample posts and synonyms to the term pregnant. A list of drugs was built with the generic and brand names of the top 10 prescribed opioids among commercially insured pregnant women in the United States [61] and commonly abused prescription opioids and heroin listed by the National Institute on Drug Abuse [11]. Opioid antagonists as MAT medications were also included. The list of 36 drugs can be found in Multimedia Appendix 2. Due to the nature of the string-matching query, false-positive posts were discarded during the coding process. For example, nonpregnant SUD recovery participants may use the word expecting in the context of anticipating an outcome.

\section{Data Analysis}

The unit of analysis is an initiating post that refers to pregnancy and opioids and does not include its comments. We performed an inductive thematic analysis on the qualifying posts following the procedures outlined by Braun and Clarke [62]. An inductive approach is driven by data without forcing emerging themes to a pre-existing coding framework [62]. The sample size was determined by the saturation principle, namely, coding was conducted until additional samples yielded no additional insights into the topic of research [63].

Two researchers (a doctoral student with a public health background and a master's student with a nursing background) iteratively annotated the same set of 200 randomly sampled posts divided into 3 coding runs. We first annotated 100 posts and recorded all appearing concepts, which were then grouped into key themes to form a codebook. For example, upon seeing many posts that described efforts of reducing the opioid dosage, we created the themes opioid experience, trimester, recovery stage, and recovery method, as it was clear that women usually mentioned their opioid experience and stage of gestation as a context for discussing the recovery methods and their recovery progress. Second, we annotated 50 additional posts and refined the codebook by placing similar concepts together. For example, inquiries on neonatal withdrawal were combined with general questions about the drug safety of opioids as adverse effects of gestational opioid use. Third, we annotated another 50 posts to confirm that no new concepts emerged from the annotation to reach saturation. The development of the codebook was supervised by an experienced researcher in human-computer interaction. The definitions and exemplary quotes of the key themes and concepts are provided in Table 1. Among the variables, up to 3 (the maximum number found in the posts) emotions and self-management support needs were annotated, as participants can express more than one concept (emotion or concern) in the same post. To measure interrater reliability, the annotations have a Cohen kappa of 0.863 , which suggests a high level of agreement. Interpretative differences were discussed among the 3 researchers and resolved. 
Table 1. Codebook.

\begin{tabular}{|c|c|}
\hline Study aim, theme, and concept definition & Example \\
\hline \multicolumn{2}{|l|}{ Study aim 1} \\
\hline \multicolumn{2}{|l|}{ Opioid experience } \\
\hline $\begin{array}{l}\text { Opioid naïve: } \\
\text { - Temporary use of opioid prescriptions for acute pain lasting fewer } \\
\text { than } 3 \text { months }\end{array}$ & $\begin{array}{l}\text { - "I had stomach pains and went to the emergency room. The } \\
\text { doctor gave me morphine." [P3660] }\end{array}$ \\
\hline $\begin{array}{l}\text { Opioid misuse: } \\
\text { - } \quad \text { Meeting one or more DSM-V }{ }^{\mathrm{a}} \text { diagnostic criteria for } \mathrm{OUD}^{\mathrm{b}}[64] \\
\text { - } \quad \text { Receiving treatment for OUD }\end{array}$ & $\begin{array}{l}\text { - "I have been self-medicating myself a total of } 18.75 \mathrm{mg} \text { daily } \\
\text { for about a year and a half. When I stopped, I experienced } \\
\text { withdrawal symptoms! Pretty intense ones too." [P90] } \\
\text { "I'm currently on methadone for an opiate addiction." [P1600] }\end{array}$ \\
\hline Unable to determine & $\begin{array}{l}\text { - "I am } 3 \text { weeks pregnant and on Norco, Flexeril, Xanax. I have } \\
\text { been taking them for } 2 \text { years." [P1830] }\end{array}$ \\
\hline
\end{tabular}

\section{Recovery stage}

Precontemplation:

- No mention of interest in reducing the opioid dosage

Contemplation:

- Expressing interest in reducing the dosage

Action:

- Describing experience during withdrawal or relapse

No misuse

\section{Recovery method}

Tapered withdrawal (self-managed):

- Describing preference for gradually reducing the dosage of opioids

Sudden discontinuation (self-managed):

- Using expressions that indicate full discontinuation of opioids

Undecided self-recovery:

- Not specifying a particular method but expressing interest in dosage reduction on one's own

Professional treatment:

- Receiving substance use treatment from professionals

MAT $^{\mathrm{c}}$ (source unknown):

- Using MAT medications from unspecified sources

Not applicable:

- Women who did not have opioid misuse or not pursuing recovery

\section{Trimester}

First trimester:

- $0-13$ weeks

Second trimester:

- 14-27 weeks
- 'I've been taking Vicodin and Percocet and I'm 20 weeks pregnant." [P5357]

- " I am ready and would like to quit the suboxone cold turkey." [P4191]

- "I am on day 2 of detoxification. How long till I feel better?" [P4074]

- $\quad$ "I am 38 weeks pregnant and my Ob prescribed me Percocet for kidney stones. I passed the stone today, so I won't be needing the pain killers anymore.” [P6315]

- "I have been detoxing for 2 months and have gone down to 29 mgs." [P1649]

- $\quad$ "I have 2 weeks left till my delivery date I stopped taking the Norco today." [P1339]

- "I know I can't do this cold turkey and am unsure of my will power to taper." [P6576]

- "I take the methadone daily at a clinic near where I live." [P1600]

- “Is it safe to use Suboxone while being pregnant?” [P6066]

- $\quad$ "I'm 27 weeks pregnant and have peed blood, and my sides where my kidneys are have been hurting really bad. I' $m$ trying not to take the Tylenol with codeine, but I might have to if it keeps getting worse.” [P17]

- "I have just found out I am 6 weeks pregnant.” [P6434]

- "I am currently 22 weeks pregnant with my second child." [P3644] 


\begin{tabular}{ll}
\hline Study aim, theme, and concept definition & Example \\
\hline $\begin{array}{l}\text { Third trimester: } \\
\text { 28+ weeks }\end{array}$ & $\begin{array}{c}\text { "I am } 39 \text { weeks pregnant." [P5896] } \\
\text { "I think I'm on the right path now, but I'm scared it will still } \\
\text { be in my system when I have the baby." [P460] }\end{array}$
\end{tabular}

\section{Study aim 2}

\section{Self-management support needs-informational}

Potential adverse effects of gestational opioid use

- Neonatal withdrawal

- Open-ended inquiry

Self-managed withdrawal

Pain management safe for pregnancy

Legal procedures

Navigating offline support systems:

- Looking for recommendations of treatment facilities

- Interacting with providers

- Interacting with caretakers

Other pregnancy concerns

\section{Appropriateness of tapering schedule}

Appropriate:

- The tapering plan is consistent with clinical guidelines

Inappropriate:

- The tapering plan is too rapid

Unclear:

- Not enough information to determine appropriateness

\section{Self-management support needs-emotional}

Seeking emotional support
- "I was just wondering if my baby could possibly withdrawal from these?" [P6342]

- “Has anyone taken this and (was) baby ok?” [P217]

- $\quad$ "Has anyone had any good stories with getting lowered slowly off it?" [P12765]

- "I am prescribed Percocet for pain. Is it bad for baby, is there a best alternative?" [P1283]

- $\quad$ "I need to know if they can take my baby because of this prescription showing up?" [P5143]

- "If anyone knows of an OBGYN that takes [insurance name] and is familiar with my situation, or a pain management doc that deals with pregnancies and also takes my insurance...just SOMEWHERE to start." [P141]

- 'I'm not sure what to do anymore. I don't want my doc to think I'm abusing them or selling then because I swear I'm not!" [P8]

- 'I just don't want to bring up my drug use to my mom because I know it's going to hurt her. I don't know what to do or what to say that doesn't have my mom worry about my baby's healthy." [P3413]

- "I am not sure if I have felt the baby move yet, I am 18 weeks today. Is that ok?" [P6689]

- No instances were found.

- "I took 3, $30 \mathrm{mg}$ for the past few days and I took 2, $30 \mathrm{mg}$ today. I am going to take 1, $30 \mathrm{mg}$ tomorrow, 15 the next and half that the following." [P6844]

- "Can I ween myself off of Methadone slowly, very slowly?" [P3391]

- "Some days I have a hard time staying positive. Please if anyone is available to talk with me, I would really appreciate it.” [P3899] 


\begin{tabular}{|c|c|}
\hline Study aim, theme, and concept definition & Example \\
\hline 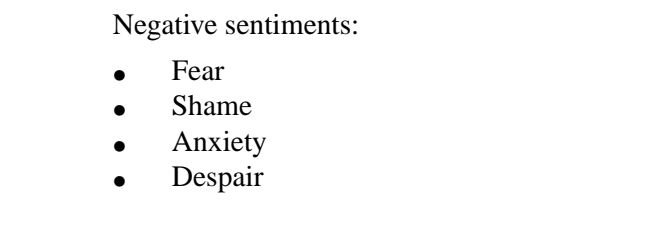 & $\begin{array}{l}\text { - "I am terrified of losing him." [P3545] } \\
\text { - "I am very ashamed." [P90] } \\
\text {-I am planning to cut down and then quit because I'm worried, } \\
\text { even though doctors say they are ok." [P369] } \\
\text { "I am so ashamed, scared, and lonely! I feel hopeless!" } \\
\text { [P4608] }\end{array}$ \\
\hline $\begin{array}{l}\text { Mixed sentiment: } \\
\text { - } \quad \text { Cautious optimistic }\end{array}$ & $\begin{array}{l}\text {-I feel much more optimistic about beating my addiction for } \\
\text { good after coming to this forum. It's hard when you have no } \\
\text { one to talk to or share experiences with." [P2137] }\end{array}$ \\
\hline $\begin{array}{l}\text { Positive sentiment: } \\
\text { - } \quad \text { Positive emotions, such as hope and love }\end{array}$ & - No instances were found. \\
\hline
\end{tabular}

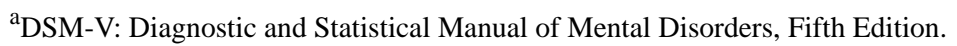

bOUD: opioid use disorder.

${ }^{\mathrm{c}}$ MAT: medication-assisted treatment.

Furthermore, women's common beliefs were compared with the scientific literature and clinical guidelines to discern any divergence. An experienced clinical psychologist annotated whether misconception existed compared with clinical guidelines in the self-guided withdrawal plans described by participants [65].

\section{Data Reporting}

Themes from inductive coding were grouped in the results to address the 2 study aims. First, the characteristics of OHC participants (study aim 1) are represented by themes coded under Opioid experience, Recovery stage, Recovery method, and Trimester. Second, the self-management support needs (study aim 2) are represented by concepts coded under self-management support needs-informational and self-management support needs-emotional and complemented by the themes Appropriateness of tapering schedule and Sentiment.

\section{Results}

\section{Metadata}

The search query yielded 3559 posts between 2000 and 2019. Posts appeared in 201 subgroups related to substance misuse (2096/3559, 58.89\%), pregnancy $(680 / 3559,19.11 \%)$, and others $(783 / 3559,22.00 \%)$, such as neurology and back pain. The mean number of drug names mentioned per post was 1.3 (SD 0.7). The mean character count per post was 1411.2 (SD 1313.7).

\section{Study Aim 1: Characteristics of Pregnant Women With Opioid Use in OHC}

The majority $(150 / 200,75.0 \%)$ of women who took opioids during pregnancy in the $\mathrm{OHC}$ (the study population) met one or more criteria from the Diagnostic and Statistical Manual of Mental Disorders, Fifth Edition [64] for a potential OUD diagnosis, which we refer to as opioid misuse as we were unable to make a formal clinical diagnosis. Close to half (94/200, $47.0 \%$ ) of the study population were in the process of pursuing dosage reduction (ie, action stage), with another 31 participants $(31 / 200,15.5 \%)$ considering but not yet initiating a reduction in dosage (ie, contemplation stage; Table 2). In terms of recovery method, self-managed withdrawal was more common than professional treatment $(P<.001)$. This indicates that women in the $\mathrm{OHC}$ primarily elect to self-manage their attempts at dosage reduction during pregnancy.

Gestationally, the women were primarily in their first or third trimesters, and notably, the percentage of women not pursuing recovery (ie, precontemplation stage) decreased $(P=.11)$ and the percentage of those in action increased $(P=.16)$ from the first to the third trimester, although the difference was not statistically significant (Figure 1). 
Table 2. Characteristics of women inquiring about opioid use in the online health communities $(\mathrm{N}=200)$.

\begin{tabular}{|c|c|}
\hline Characteristic & Participants, n (\%) \\
\hline \multicolumn{2}{|l|}{ Opioid experience } \\
\hline Opioid naïve & $22(11.0)$ \\
\hline Opioid misuse & $150(75.0)$ \\
\hline Unable to determine & $28(14.0)$ \\
\hline \multicolumn{2}{|l|}{ Recovery stage } \\
\hline Precontemplation & $51(25.5)$ \\
\hline Contemplation & $31(15.5)$ \\
\hline Action & $94(47.0)$ \\
\hline No misuse & $24(12.0)$ \\
\hline \multicolumn{2}{|l|}{ Recovery method } \\
\hline \multicolumn{2}{|l|}{ Self-managed withdrawal } \\
\hline Tapered withdrawal & $40(20.0)$ \\
\hline Sudden discontinuation & $35(17.5)$ \\
\hline Undecided & $15(7.5)$ \\
\hline Professional treatment & $29(14.5)$ \\
\hline Medication-assisted treatment (unknown sources) & $6(3.0)$ \\
\hline Not applicable & $75(37.5)$ \\
\hline \multicolumn{2}{|l|}{ Trimester } \\
\hline First & $61(30.5)$ \\
\hline Second & $49(24.5)$ \\
\hline Third & $66(33.0)$ \\
\hline Unspecified & $24(12.0)$ \\
\hline
\end{tabular}


Figure 1. Proportions of the recovery stages by trimester.

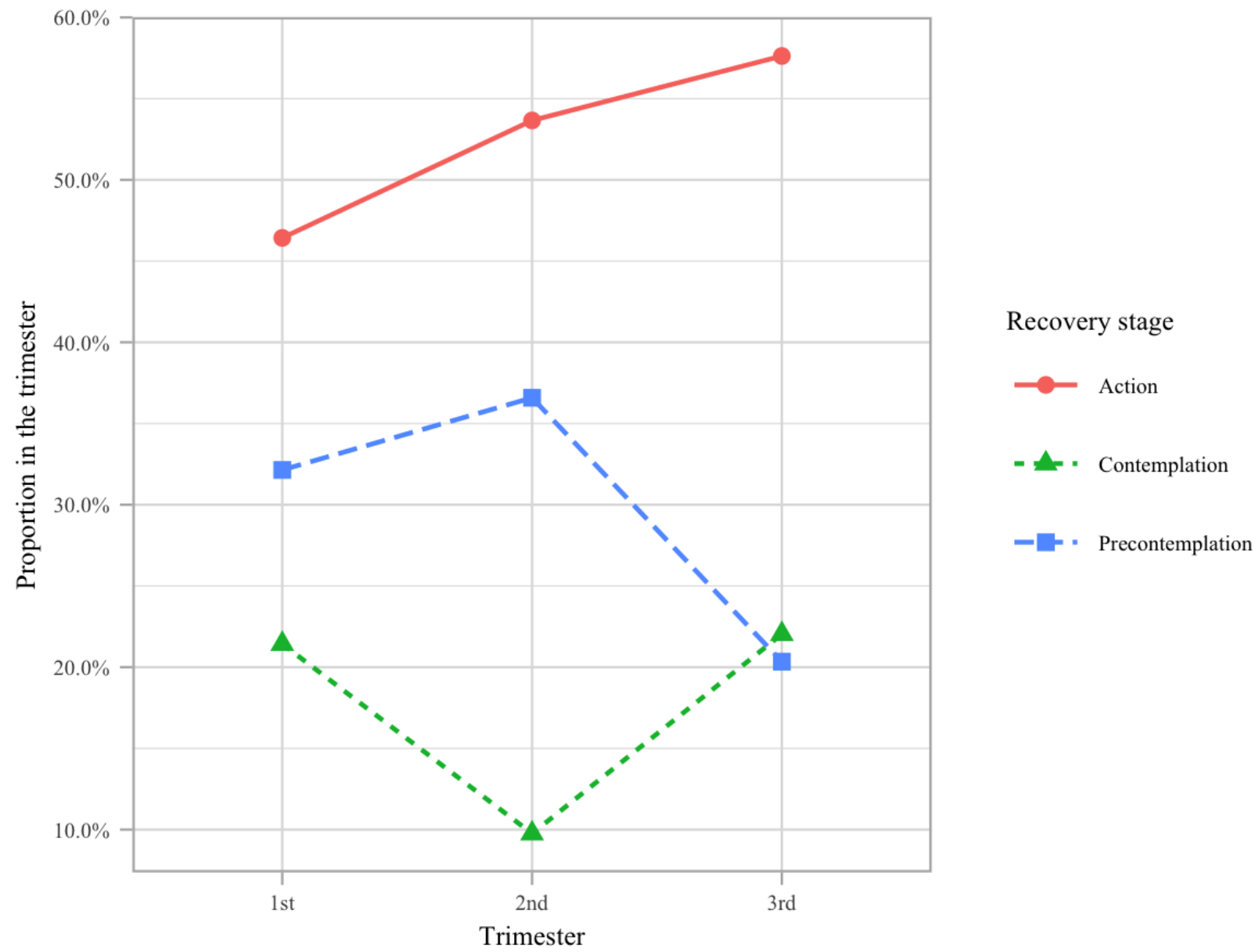

\section{Study Aim 2: Self-Management Support Needs}

Following thematic analysis of the web posts, 6 primary themes of self-management support needs were identified, including information needs for understanding (1) the potential adverse effects of gestational opioid use, (2) self-led withdrawal, (3) the safety of continued opioid use for pain management during pregnancy, (4) legal procedures related to child protection, (5) navigating offline health care systems, and (6) needs for emotional support (Table 3). Other pregnancy concerns and posts with unspecified support needs were excluded from further analysis because they do not pertain to opioid use. The women had different self-management support needs according to their recovery stages $\left(\chi_{15}^{2}=69.5 ; P<.001\right)$. The absolute value of a standardized residual $\left(\mathrm{r}_{\text {std }}\right)$ greater than 2 indicates a strong (dis)association (Figure 2), on which we will elaborate next.

Table 3. Self-management support needs expressed in the online health community postings $(\mathrm{N}=200)$.

\begin{tabular}{ll}
\hline Themes and concepts & Participants, $\mathrm{n}(\%)$ \\
\hline Self-management support needs-informational & $99(49.5)$ \\
Potential adverse effects of gestational opioid use & $70(35.0)$ \\
Self-managed withdrawal & $20(10.0)$ \\
Pain management safety during pregnancy & $18(9.0)$ \\
Legal procedures & $9(4.5)$ \\
Navigating offline support systems & $12(6.0)$ \\
Self-management support needs-emotional & $5(2.5)$ \\
Seeking emotional support & $4(2.0)$ \\
Excluded & \\
Other pregnancy concerns & \\
Unspecified & \\
\hline
\end{tabular}


Figure 2. Standardized residuals of associations between self-management support needs and recovery stages.

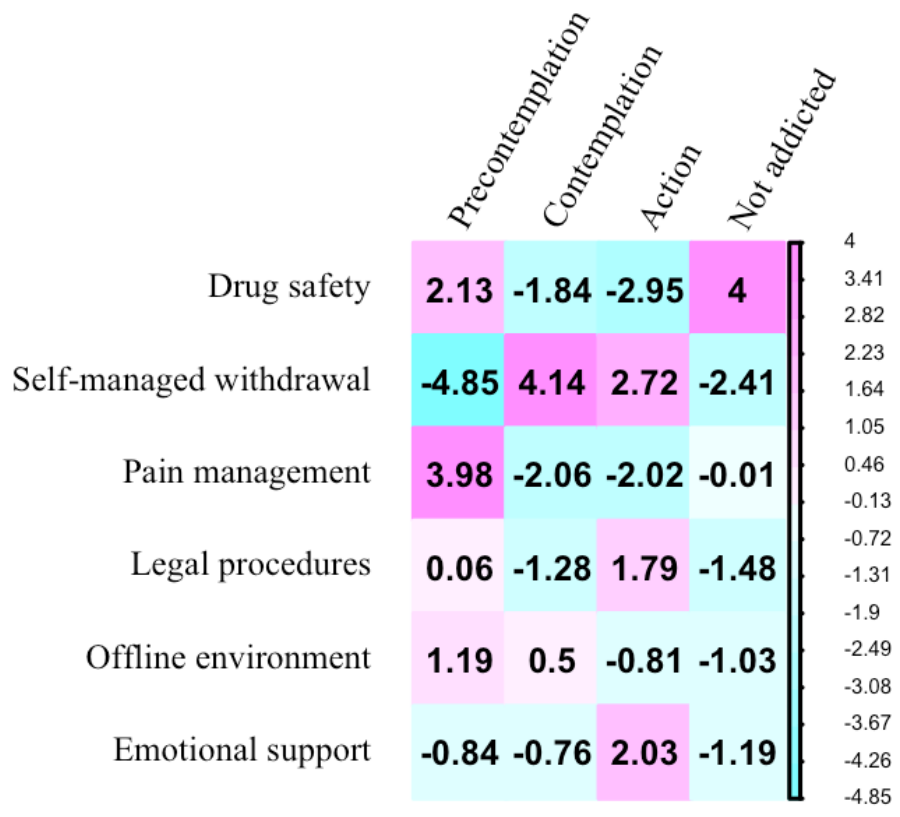

\section{Potential Adverse Effects of Gestational Opioid Use}

The most common concern $(99 / 200,49.5 \%)$ of the study population was the potential adverse effects of opioids on the fetuses. In particular, the questions on drug safety have a high level of homogeneity and can be simply divided into 2 categories: general inquiry as in "was your baby okay?" [P3614] and specific inquiry on the potential of neonatal withdrawal as in "I am scared to death my baby will have withdrawals" [P16]. These concerns were primarily seen among those who did not consider treatment for opioid misuse $\left(\mathrm{r}_{\text {std }}=2.13\right)$ or did not have a misuse $\left(r_{\text {std }}=4.00\right)$, whereas those in active pursuit of recovery were least concerned with the drug safety in their posts $\left(r_{\text {std }}=-2.95\right.$; Figure 2).

\section{Self-Managed Withdrawal}

Questions about how to reduce opioid dosage during pregnancy were the second most common $(70 / 200,35.0 \%)$, primarily among those contemplating $\left(\mathrm{r}_{\text {std }}=4.14\right)$ or undergoing $\left(\mathrm{r}_{\text {std }}=2.72\right)$ treatment of opioid misuse (Figure 2). These concerns included (1) comparing strategies to reduce opioid dosage, (2) discussing withdrawal schedules, (3) enduring withdrawal-related hardships, and (4) dealing with the aftermath of relapses.

First, women contemplating dosage reduction used the $\mathrm{OHC}$ as a sounding board to plan their course of action in the absence of professional advice. They debated the risks and benefits of withdrawal during pregnancy and how to do so safely. They were concerned about the impact on the fetus if withdrawal symptoms occurred during their pregnancy:
I'm scared about the withdrawals of MS Contin, for which I'm fully prepared, but scared it will harm my child? [P6419]

They also compared sudden discontinuation to tapered withdrawal:

I considered quitting cold turkey, but I have read that it is a bad idea. Would tapering be a good idea? What is a good taper method? [P2325]

Although this shows some women were aware of the disadvantages of sudden discontinuation, tapered withdrawal $(40 / 200,20.0 \%)$ and sudden discontinuation $(35 / 200,17.5 \%)$ were equally popular among the study population $(P=.61)$.

Second, once committed to decreasing their opioid dosage, the women may describe a detailed tapering schedule in the $\mathrm{OHC}$ to solicit peer feedback:

Should I just do half of what I have been for a few days, then cut it in half again, do that for a couple days, then go for nothing?! I really don't know what to do, that's why I am asking for help. [P1628]

Of all the women who indicated an interest in tapered withdrawal, only $23 \%$ (9/40) provided specific information on how they intended to do so, suggesting that most did not have a structured plan on how to taper. Furthermore, all of these plans were deemed too rapid (Table 4) based on clinical guidelines and could increase the risk of painful withdrawal symptoms [65].

Table 4. Appropriateness of tapering schedule $(\mathrm{N}=40)$.

\begin{tabular}{ll}
\hline Appropriateness & Participants, $\mathrm{n}(\%)$ \\
\hline Unclear & $31(78)$ \\
Inappropriate (too rapid) & $9(22)$ \\
Appropriate & $0(0)$ \\
\hline
\end{tabular}


Third, after initiating withdrawal, the women turned to the $\mathrm{OHC}$ for practical advice and emotional support when undergoing the hardship of withdrawal, sometimes stemming from the lack of a proper tapering schedule:

Just started detox on tramadol today. I feel like hell and my legs are killing me! I'm 26 hours into it. How much more do I need to endure? [P2423]

As a result of significant withdrawal symptoms, they were prone to setbacks and relapses:

Unfortunately, I relapsed and slowly started using until now (37 weeks). I have stopped a couple of times but have had issues because of withdrawal fears. [P5992]

To combat the demoralizing impact of relapses, some women looked to the $\mathrm{OHC}$ to hold them accountable:

I am just looking for some support, accountability and encouragement as I feel so alone, scared and terrible about my relapse and lying to my love. [P3545]

Figure 3. Proportions of the recovery methods by trimester.
These experiences highlight the absence of structure and support with self-managed withdrawal as compared with being in a clinical program where physician supervision and evidence-based therapies are provided to help patients manage their dosage reduction process more effectively.

Fourth, the repeated attempts and failures to decrease opioid use during pregnancy were not only physically taxing and emotionally draining but also meant that the women with clandestine opioid use would have no other perceived choice but to resort to sudden discontinuation when the date of delivery approached in hope of a negative drug test, despite the dangers of doing so abruptly. Women in this position asked:

How long will it take for the test to be negative if I stop today? [P5891]

The commonness of this risky approach is evident in the increasing percentage $(P=.70)$ of women attempting sudden discontinuation of dosage and the decreasing percentage $(P=.17)$ of tapered withdrawal during the third trimester (Figure 3), although the changes were not statistically significant.

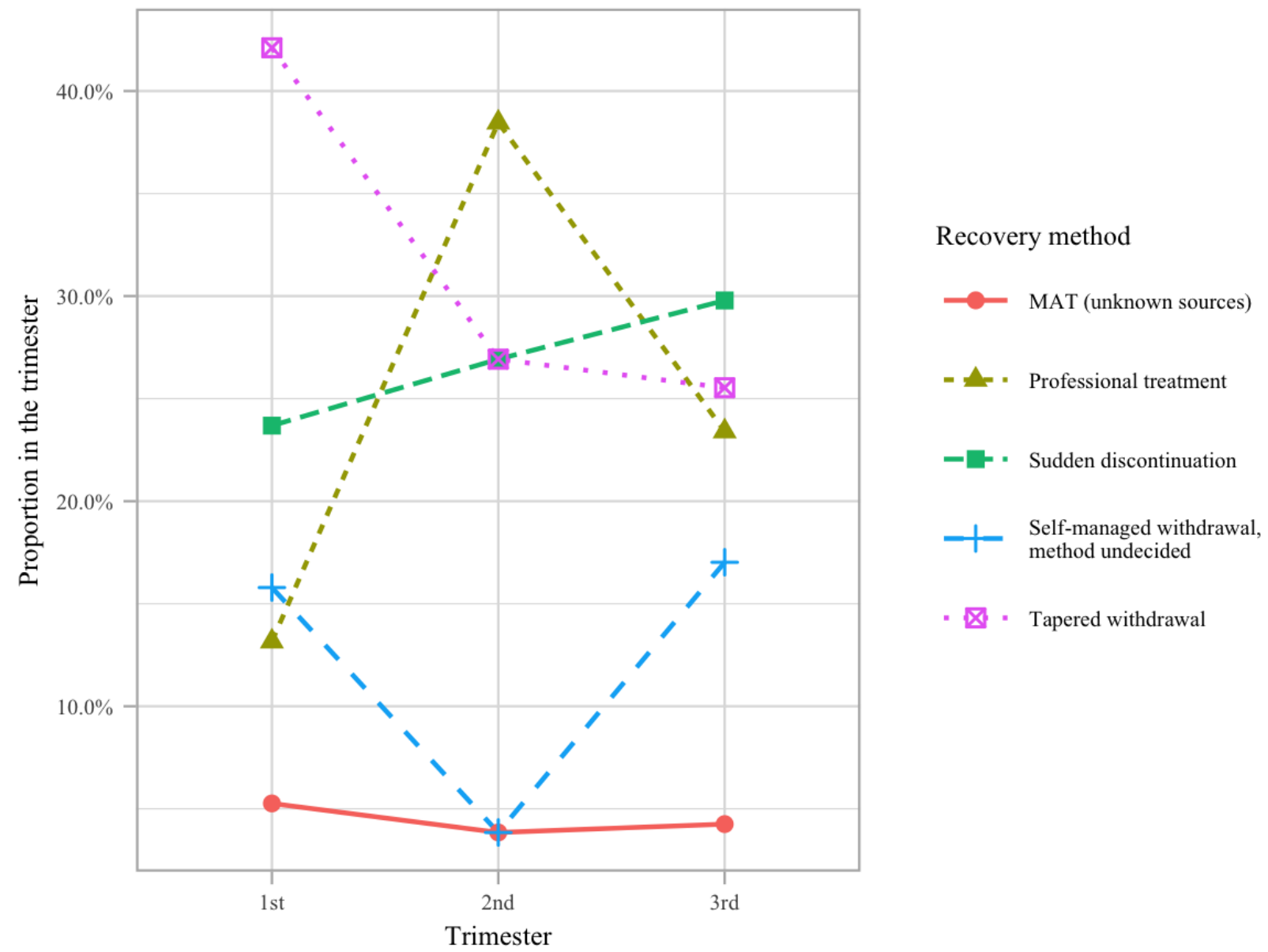

\section{Pain Management}

Women using opioids for chronic pain management before becoming pregnant faced the dilemma of leaving their severe pain untreated or risking side effects to their fetus. They had difficulty transitioning to gestational opioid use:
I have been in pain management for 3 years due to a dislocated hip. Apparently neither my OB nor primary care doctor have ever dealt with "my situation" before. [P141] 
In looking for safe pain medications to take during pregnancy, they $(20 / 200,10.0 \%)$ viewed peers' experience as empirical evidence and second opinions to professional advice:

I have 4 discs missing in my spine. I am now 4 months pregnant and my doctor has taken me off everything!!!

Does anyone know what is safe for the baby? [P6486]

As they continue to take opioids during pregnancy, concerns related to pain management are mostly associated $\left(\mathrm{r}_{\text {std }}=3.98\right)$ with those in the precontemplation stage (Figure 2).

\section{Understanding Legal Procedures}

Concerns related to Child Protective Services (CPSs) procedures were present in $9.0 \%$ (18/200) of the posts. These concerns were more common among women in the recovery stage of action $\left(r_{\text {std }}=1.79\right)$ than in other stages (Figure 2). Although the regulation and laws related to child protection from drug use are obscure to laypersons, the vague idea of losing parental guardianship looms large. Pregnant women with opioid misuse in the $\mathrm{OHC}$ described intense fear of being identified as using and consequently losing parental guardianship of their newborn and the goodwill of their direct support systems:

I am scared to death of having to deal with child protection service especially since none in my family knows about any of this and the fear of my child being taken away from me. [P16]

They inquired about the role of hospitals in reporting drug use instead of directly asking their providers:

Will child services still get involved? I have heard that doctors do these types of things and contact these types of people behind your back? [P3776]

Notably, those who used unprescribed MAT medications to self-treat OUD (6/200, 3.0\%) may still be held accountable for illegal possession and opioid use during pregnancy.

\section{Navigating Offline Support Systems}

A few women $(9 / 200,4.5 \%)$ also requested strategies for navigating their offline support systems, including recommendations for treatment facilities (4/200, 2.0\%), advice for interacting with health care providers $(4 / 200,2.0 \%)$, and disclosing opioid use with their family members $(1 / 200,0.5 \%)$. These concerns were not particularly associated with one recovery stage. Accessing specialized prenatal care for women with opioid use or finding substance treatment programs that accept pregnant women presented a challenge. Locating a specialty program proved to be difficult even with an obstetrician's referral:

\section{My obstetrician had made me an appointment with a therapist, who tells me she doesn't even see pregnant women! I got some numbers for the methadone clinic and other places but yet again no one will help a pregnant woman. [P3855]}

This post was made after 2010, which is a decade after the passing of the Drug Addiction Treatment Act (DATA) of 2000, which allows trained physicians including obstetricians to treat opioid dependency with MAT medications. Women also consulted the $\mathrm{OHC}$ for strategies on how to best interact with their providers and caretakers to explain personal circumstances involving opioid usage and building rapport (examples are given in Table 1).

\section{Seeking Emotional Support}

Besides the needs for informational support, a few women $(12 / 200,6.0 \%)$ explicitly requested emotional support:

Please send me some words of encouragement. [P3545]

In contrast, a high number of posts $(117 / 200,58.5 \%)$ described negative emotions, including fear, shame, anxiety, and despair (Table 5; examples are given in Table 1). In other words, only about 1 out of 10 women who experienced negative emotions sought to address their emotional needs with the help of the OHC. Importantly, expressing negative emotions did not modify the women's likelihood of pursuing (ie, action or contemplation) dosage reduction $\left(\chi_{1}^{2}=0.1 ; P=.75\right)$.

Table 5. Sentiment $(\mathrm{N}=200)$.

\begin{tabular}{ll}
\hline Sentiment & Participants, $\mathrm{n}(\%)$ \\
\hline Negative & $117(58.5)$ \\
Not specified & $82(41.0)$ \\
Mixed & $1(0.5)$ \\
Positive & $0(0.0)$ \\
\hline
\end{tabular}

\section{Discussion}

\section{Principal Findings}

The majority of pregnant women in the OHC exhibited signs of opioid misuse, with approximately two-thirds of them pursuing recovery. Self-managed withdrawal of opioid use was more common than professional treatment. The following 6 identified themes highlighted women's self-management support needs: (1) providing clarity on the impact of opioid drugs on pregnancy; (2) providing clinically validated information on how to scientifically reduce opioid dosage; (3) providing guidelines on safe pain management practice during pregnancy; (4) providing information on local CPSs procedures, including the hospital's role in reporting; (5) providing strategies for interacting with and obtaining support from offline support systems; and (6) providing emotional support for those experiencing negative emotions.

The study population relied heavily on the OHC to provide guidance in the absence of professional care and in-person 
support, which differentiates them from other patient groups that usually use online support groups as a supplement to traditional health care services or in-person support groups $[66,67]$. Formal evaluation and proper treatment recommendations were lacking for pregnant women in the $\mathrm{OHC}$ who chose self-managed withdrawal. Despite their resolve to reduce opioid dosage, women were vulnerable to the pitfalls of misinformation (eg, overly aggressive tapering schedules) and could easily experience relapses that may cause distress in both the mother and fetus.

\section{Indirect Emotional Support}

Experiencing negative emotions is commonplace for the study population, but explicitly requesting emotional support is not. Furthermore, although positive emotions are shown to be a facilitator of self-efficacy, which is a key construct in the social cognitive theory for effecting health behavior change $[68,69]$, the opposite may not be true: experiencing negative emotions does not modify the women's likelihood of pursuing dosage reduction. This contrast, on the one hand, shows that women with opioid use or misuse during pregnancy were preoccupied with seeking information to resolve their predicament, and on the other hand, may suggest that their emotional needs were met by the $\mathrm{OHC}$ in indirect ways. First, information seeking is frequently used as a coping response because it helps assess the degree of threat associated with a stressor, thereby reducing uncertainty in health care $[69,70]$. Second, although not directly soliciting emotional support, participants in the $\mathrm{OHC}$ voluntarily shared detailed accounts of their offline experiences while seeking information on self-managed withdrawal, pain management, and strategies for navigating health care environments. Emotional regulation in the form of venting feelings is within the underpinning of the transactional model of stress and coping [70,71]. Cathartic release and negation of offline frustration are also themes related to the negotiation of self-management support [35].

\section{Challenging the Scope of Self-Management Support}

It is worth noting that self-management support interventions are typically developed by health care professionals to complement standard care. For example, self-management support for mental health typically focuses on patient education, medication adherence, relapse prevention, and coping strategies [28]. Among the 6 self-management support needs identified, the second need for patient education on how to scientifically reduce opioid dosage may challenge the realm of what is commonly accepted for self-management support in that self-managed withdrawal implies evading standard care, instead of complementing it. Self-managed withdrawal without professional supervision can be dangerous and should be discouraged. Here, we take the view that until there are enough specialized resources to treat pregnant women with opioid misuse and done so without legal penalization, there will always be women compelled to pursue self-managed withdrawal. Therefore, harm reduction via patient education as to how to safely taper is imperative.

\section{Policy Considerations}

Although DATA was passed in 2000, women in the OHC still reported difficulty in obtaining MAT from their obstetricians' office years later. To facilitate the initiation of recovery for pregnant women with opioid misuse, it is imperative to increase the number of obstetricians who are waivered buprenorphine prescribers and to increase the number of opioid treatment programs that cater to pregnant women. As of January 2020, approximately $10 \%$ of US physicians have received the DATA waiver [72]. Coverage in rural areas is particularly needed. For example, only $53 \%$ of outpatient buprenorphine prescribers accepted pregnant patients in Appalachian states as of 2017 [73]. Moreover, only $24 \%$ of opioid treatment facilities offer special programs for pregnant or postpartum women [1].

The popularity of self-management in the OHC highlights women's needs for support in reducing their opioid dosage and their fear of seeking professional care. This indicates that legal penalization can be detrimental to the well-being of both the mother and child, as women avoid prenatal visits [4]. Many pregnant women presume that they will face negative consequences if they disclose drug use to their obstetricians, missing an important window in which to initiate recovery. Universal screening of substance use for pregnant women without legal implications may help dissolve the distrust between some patients and their providers.

\section{Technology Design for Harm Reduction}

Although technology may not be able to directly change the medical and legal landscape, it can be used to tackle challenges faced by pregnant women with opioid misuse. Digital interventions have demonstrated small to modest effects in supporting people in recovery from SUDs [74,75]; however, only a minority of evidence-based self-help interventions have functional websites for general use [76]. A study on popular alcohol reduction apps found that common behavior change techniques employed facilitate self-recording, provide information on the consequences of excessive alcohol use, and provide feedback on performance [77]. As mentioned earlier, the social cognitive theory offers a framework to create positive behavior changes $[68,69]$. Facilitation and self-regulation are 2 concepts that are particularly applicable to better technological designs in the context of this study.

Facilitation refers to providing tools and resources to make new behaviors easier to establish. OHCs can facilitate (1) geo-specific information dissemination and (2) clinically validated tapering schedules for those who opt for self-management. Specifically, given the regional variations in law enforcement and resources of specialized care, organizing information specific to geographic areas may facilitate online discussions relevant to participants' local environments. For those opting for self-managed withdrawals, we envision an online calculator that can account for women's historical opioid dosage and gestational stage and generate a personalized tapering schedule based on current guidelines (albeit while expressing strong encouragement to bring one's opioid use to the attention of their health care professionals). 
Furthermore, self-regulation refers to controlling oneself through self-monitoring, goal setting, feedback, and the enlistment of social support. Although undergoing withdrawal, women in the OHC often lack structured social support that can hold them accountable and support them in their efforts to stay on track. Peer-led 12-step groups have been shown to improve accountability and recovery prospects for participants [78]. We envision OHC's incorporating the structured aspect of effective peer support programs by creating an environment in which participants can perform daily check-ins, display badges of withdrawal progress, and easily reach out to peers for support and accountability.

\section{Limitations and Future Work}

The findings of this study should be interpreted with limitations. First, the reported self-recovery trends are representative of those seeking help in the OHC. The percentage of self-managed withdrawal in the general population may be lower than that reported in this study, as those opting for self-management may have a greater propensity for participating in the $\mathrm{OHC}$ discussions to seek help. Our findings, however, are meaningful in better understanding the $\mathrm{OHC}$ population that appears to require relevant, clinically validated information. Second, only 200 posts for the $\mathrm{OHC}$ were analyzed. Thematic analyses are commonly applied to sociobehavioral studies using semistructured interviews with an average of 30 participants (SD 18.7) [79]. Qualitative studies of online content have varying sample sizes, usually ranging from 100 to 2000 $[31,41,43,45,46,50,80]$. We iteratively coded 200 posts and reached concept saturation within this number. In other words, had new concepts emerged during the annotation of the last 50 randomly sampled posts, we would continue sampling additional posts. Third, comments in response to the initiating posts by women with opioid misuse were not analyzed, as this study focused on the beliefs and actions of those attempting self-management at the moment of posting. Previous research shows that most comments in OHCs for chronic health conditions have an element of social support, primarily including validation and empathy [80]. In light of our observation on the imbalance of requests for informational and emotional support, future research should examine how the $\mathrm{OHC}$ audience responds to the posts. Fourth, qualitative analysis was performed on a cross-sectional rather than a longitudinal sample set. A future direction may be to follow OHC participants throughout the course of their pregnancy and postpartum to better understand the outcome of their proposed self-management work.

\section{Conclusions}

OHCs provide vital self-management support for pregnant women with opioid use or misuse. Women pursuing self-managed dosage reduction are prone to misinformation and repeated relapses, which can result in extreme measures to avoid testing positive for drug use at labor. The study findings provide evidence for public policy considerations, including universal screening of substance use for pregnant women, emphasis on treatment rather than legal punishment, and further expansion of the DATA waiver training program. The improvement of online platforms that can organize geo-relevant information, dispense clinically validated withdrawal schedules, and offer structured peer support is envisioned for harm reduction among pregnant women who opt for self-management of opioid misuse.

\section{Acknowledgments}

This work was supported in part by the National Science Foundation under Grant NSF-1741306, Grant IIS-1650531, and Grant DIBBS-1443019. Any opinions and conclusions or recommendations expressed in this study are those of the author(s) and do not necessarily reflect the views of the National Science Foundation.

\section{Conflicts of Interest}

None declared.

\section{Multimedia Appendix 1}

Definitions related to opioid use and treatment.

[DOCX File, 22 KB-Multimedia Appendix 1]

\section{Multimedia Appendix 2}

List of 36 drug names related to opioid use.

[DOCX File, 14 KB-Multimedia Appendix 2]

\section{References}

1. Smith K, Lipari R. Women of childbearing age and opioids. The CBHSQ Report. Rockville, MD: Center for Behavioral Health Statistics and Quality, Substance Abuse and Mental Health Services Administration; 2017. URL: https://www. samhsa.gov/data/sites/default/files/report 2724/ShortReport-2724.pdf [accessed 2021-01-05]

2. Ko JY, D'Angelo DV, Haight SC, Morrow B, Cox S, Salvesen von Essen B, et al. Vital Signs: Prescription Opioid Pain Reliever Use During Pregnancy - 34 U.S. Jurisdictions, 2019. MMWR Morb Mortal Wkly Rep 2020 Jul 17;69(28):897-903 [FREE Full text] [doi: 10.15585/mmwr.mm6928a1] [Medline: 32673301] 
3. Yeoh SL, Eastwood J, Wright IM, Morton R, Melhuish E, Ward M, et al. Cognitive and Motor Outcomes of Children With Prenatal Opioid Exposure: A Systematic Review and Meta-analysis. JAMA Netw Open 2019 Jul 03;2(7):e197025 [FREE Full text] [doi: 10.1001/jamanetworkopen.2019.7025] [Medline: $\underline{31298718}$ ]

4. Krans EE, Patrick SW. Opioid Use Disorder in Pregnancy. Obstetrics \& Gynecology 2016;128(1):4-10. [doi: 10.1097/aog.0000000000001446]

5. Livingston JD, Milne T, Fang ML, Amari E. The effectiveness of interventions for reducing stigma related to substance use disorders: a systematic review. Addiction 2012 Jan;107(1):39-50 [FREE Full text] [doi: 10.1111/j.1360-0443.2011.03601.x] [Medline: 21815959]

6. Klaman S, Isaacs K, Leopold A, Perpich J, Hayashi S, Vender J, et al. Treating Women Who Are Pregnant and Parenting for Opioid Use Disorder and the Concurrent Care of Their Infants and Children: Literature Review to Support National Guidance. J Addict Med 2017;11(3):178-190 [FREE Full text] [doi: 10.1097/ADM.0000000000000308] [Medline: 28406856]

7. Winklbaur B, Kopf N, Ebner N, Jung E, Thau K, Fischer G. Treating pregnant women dependent on opioids is not the same as treating pregnancy and opioid dependence: a knowledge synthesis for better treatment for women and neonates. Addiction 2008 Sep;103(9):1429-1440. [doi: 10.1111/j.1360-0443.2008.02283.x] [Medline: 18783498]

8. Stover MW, Davis JM. Opioids in pregnancy and neonatal abstinence syndrome. Semin Perinatol 2015 Dec;39(7):561-565 [FREE Full text] [doi: 10.1053/j.semperi.2015.08.013] [Medline: 26452318]

9. Committee on Obstetric Practice. Committee Opinion No. 711: Opioid Use and Opioid Use Disorder in Pregnancy. Obstet Gynecol 2017 Aug;130(2):e81-e94. [doi: 10.1097/AOG.0000000000002235] [Medline: 28742676]

10. Laslo J, Brunner J, Burns D, Butler E, Cunningham A, Killpack R, et al. An overview of available drugs for management of opioid abuse during pregnancy. Matern Health Neonatol Perinatol 2017 Feb 10;3(1):4 [FREE Full text] [doi: 10.1186/s40748-017-0044-2] [Medline: 28203387]

11. Commonly Abused Drugs Charts. National Institute on Drug Abuse. 2019. URL: https://www.drugabuse.gov/drugs-abuse/ commonly-abused-drugs-charts [accessed 2021-01-05]

12. Module 5: Assessing and Addressing Opioid Use Disorder (OUD). Centers for Disease Control and Prevention. 2021. URL: https://www.cdc.gov/drugoverdose/training/oud/accessible/index.html [accessed 2021-01-20]

13. Worley J. Recovery in substance use disorders: what to know to inform practice. Issues Ment Health Nurs 2017 Jan;38(1):80-91. [doi: 10.1080/01612840.2016.1245375] [Medline: 27901625]

14. Propublica. How States Handle Drug Use During Pregnancy. URL: https://projects.propublica.org/graphics/ maternity-drug-policies-by-state [accessed 2021-01-20]

15. Metz VE, Brown QL, Martins SS, Palamar JJ. Characteristics of drug use among pregnant women in the United States: Opioid and non-opioid illegal drug use. Drug Alcohol Depend 2018 Feb 01;183:261-266 [FREE Full text] [doi: 10.1016/j.drugalcdep.2017.11.010] [Medline: 29310077]

16. Roberts SCM, Pies C. Complex calculations: how drug use during pregnancy becomes a barrier to prenatal care. Matern Child Health J 2011 Apr 16;15(3):333-341 [FREE Full text] [doi: 10.1007/s10995-010-0594-7] [Medline: 20232126]

17. Frazer Z, McConnell K, Jansson LM. Treatment for substance use disorders in pregnant women: Motivators and barriers. Drug Alcohol Depend 2019 Dec 01;205:107652. [doi: 10.1016/j.drugalcdep.2019.107652] [Medline: $\underline{31704383}$ ]

18. Self-Management Support. Agency for Healthcare Research Quality. 2020. URL: http://www.ahrq.gov/ncepcr/tools/ self-mgmt/self.html [accessed 2021-01-05]

19. Support and Education for Patient Disease Management. Cent Dis Control Prev. URL: https://www.cdc.gov/dhdsp/pubs/ guides/best-practices/self-management.htm [accessed 2021-01-05]

20. Module 2: Self-Management Support (SMS). U.S. Department of Health \& Human Services. URL: https://www.hhs.gov/ ash/about-ash/multiple-chronic-conditions/education-and-training/curriculum/module-2-self-management-support/index. html [accessed 2021-01-05]

21. Allegrante JP, Wells MT, Peterson JC. Interventions to Support Behavioral Self-Management of Chronic Diseases. Annu Rev Public Health 2019 Apr 01;40:127-146. [doi: 10.1146/annurev-publhealth-040218-044008] [Medline: $\underline{30601717]}$

22. Hanlon P, Daines L, Campbell C, McKinstry B, Weller D, Pinnock H. Telehealth Interventions to Support Self-Management of Long-Term Conditions: A Systematic Metareview of Diabetes, Heart Failure, Asthma, Chronic Obstructive Pulmonary Disease, and Cancer. J Med Internet Res 2017 May 17;19(5):e172 [FREE Full text] [doi: 10.2196/jmir.6688] [Medline: 28526671]

23. Greenwood DA, Gee PM, Fatkin KJ, Peeples M. A Systematic Review of Reviews Evaluating Technology-Enabled Diabetes Self-Management Education and Support. J Diabetes Sci Technol 2017 Sep;11(5):1015-1027. [doi:

10.1177/1932296817713506] [Medline: 28560898]

24. Kessler D, Liddy C. Self-management support programs for persons with Parkinson's disease: An integrative review. Patient Educ Couns 2017 Oct;100(10):1787-1795. [doi: 10.1016/j.pec.2017.04.011] [Medline: 28465112]

25. Galdas P, Fell J, Bower P, Kidd L, Blickem C, McPherson K, et al. The effectiveness of self-management support interventions for men with long-term conditions: a systematic review and meta-analysis. BMJ Open 2015 Mar 20;5(3):e006620-e006620 [FREE Full text] [doi: 10.1136/bmjopen-2014-006620] [Medline: 25795688] 
26. Whitehead L, Seaton P. The Effectiveness of Self-Management Mobile Phone and Tablet Apps in Long-term Condition Management: A Systematic Review. J Med Internet Res 2016;18(5):e97 [FREE Full text] [doi: 10.2196/jmir.4883] [Medline: 27185295]

27. Huis In Het Veld JG, Willemse BM, van Asch IF, Groot Zwaaftink RB, Verkade P, Twisk JW, et al. Online Self-Management Support for Family Caregivers Dealing With Behavior Changes in Relatives With Dementia (Part 2): Randomized Controlled Trial. J Med Internet Res 2020 Feb 25;22(2):e13001 [FREE Full text] [doi: 10.2196/13001] [Medline: 32130142]

28. Lean M, Fornells-Ambrojo M, Milton A, Lloyd-Evans B, Harrison-Stewart B, Yesufu-Udechuku A, et al. Self-management interventions for people with severe mental illness: systematic review and meta-analysis. Br J Psychiatry 2019 May;214(5):260-268 [FREE Full text] [doi: 10.1192/bjp.2019.54] [Medline: 30898177]

29. Poole R, Smith D, Simpson S. How Patients Contribute to an Online Psychoeducation Forum for Bipolar Disorder: A Virtual Participant Observation Study. JMIR Ment Health 2015 Jul;2(3):e21 [FREE Full text] [doi: 10.2196/mental.4123] [Medline: 26543925]

30. Lucock M, Gillard S, Adams K, Simons L, White R, Edwards C. Self-care in mental health services: a narrative review. Health Soc Care Community 2011 Nov;19(6):602-616. [doi: 10.1111/j.1365-2524.2011.01014.x] [Medline: 21749527]

31. Brown S, Altice FL. Self-management of buprenorphine/naloxone among online discussion board users. Subst Use Misuse 2014 Jun;49(8):1017-1024. [doi: 10.3109/10826084.2014.888449] [Medline: 24779501]

32. Schaub MP, Wenger A, Berg O, Beck T, Stark L, Buehler E, et al. A Web-Based Self-Help Intervention With and Without Chat Counseling to Reduce Cannabis Use in Problematic Cannabis Users: Three-Arm Randomized Controlled Trial. J Med Internet Res 2015 Oct;17(10):e232 [FREE Full text] [doi: 10.2196/jmir.4860] [Medline: 26462848]

33. Myneni S, Lewis B, Singh T, Paiva K, Kim SM, Cebula AV, et al. Diabetes Self-Management in the Age of Social Media: Large-Scale Analysis of Peer Interactions Using Semiautomated Methods. JMIR Med Inform 2020 Jun 30;8(6):e18441 [FREE Full text] [doi: 10.2196/18441] [Medline: 32602843]

34. Barrera M, Glasgow R, McKay H, Boles S, Feil E. Do Internet-Based Support Interventions Change Perceptions of Social Support?: An Experimental Trial of Approaches for Supporting Diabetes Self-Management. Am J Community Psychol 2002;30(5):654. [doi: 10.1023/a:1016369114780]

35. Allen C, Vassilev I, Kennedy A, Rogers A. Long-Term Condition Self-Management Support in Online Communities: A Meta-Synthesis of Qualitative Papers. J Med Internet Res 2016 Mar 10;18(3):e61 [FREE Full text] [doi: 10.2196/jmir.5260] [Medline: 26965990]

36. PatientsLikeMe. URL: https://www.patientslikeme.com/ [accessed 2021-01-21]

37. BabyCenter. URL: https://www.babycenter.com/ [accessed 2021-01-21]

38. Fox S, Duggan M. Health Online 2013. The Pew Research Center. 2013. URL: https://www.pewinternet.org/wp-content/ uploads/sites/9/media/Files/Reports/PIP HealthOnline.pdf [accessed 2021-01-05]

39. Mamykina L, Nakikj D. Collective Sensemaking in Online Health Forums. Proceedings of the 33rd Annual ACM Conference on Human Factors in Computing Systems 2015 Apr:3217-3226. [doi: 10.1145/2702123.2702566]

40. Mankoff J, Kuksenok K, Kiesler S, Rode J, Waldman K. Competing online viewpoints and models of chronic illness. In: Proceedings of the SIGCHI Conference on Human Factors in Computing Systems. Canada: ACM Press; 2011 May Presented at: CHI Conference on Human Factors in Computing Systems; May, 2011; Vancouver BC Canada p. 589-598. [doi: 10.1145/1978942.1979027]

41. Hartzler A, Pratt W. Managing the personal side of health: how patient expertise differs from the expertise of clinicians. $\mathrm{J}$ Med Internet Res 2011;13(3):e62 [FREE Full text] [doi: 10.2196/jmir.1728] [Medline: 21846635]

42. Costa Figueiredo M, Caldeira C, Eikey EV, Mazmanian M, Chen Y. Engaging with Health Data: The Interplay Between Self-Tracking Activities and Emotions in Fertility Struggles. In: Proc. ACM Hum.-Comput. Interact. 2018 Nov Presented at: Proc ACM Hum-Comput Interact; 2018 Nov 1; - p. 1-20. [doi: 10.1145/3274309]

43. Frost JH, Massagli MP. Social uses of personal health information within PatientsLikeMe, an online patient community: what can happen when patients have access to one another's data. J Med Internet Res 2008;10(3):e15 [FREE Full text] [doi: 10.2196/jmir.1053] [Medline: 18504244]

44. Wicks P, Massagli M, Frost J, Brownstein C, Okun S, Vaughan T, et al. Sharing health data for better outcomes on PatientsLikeMe. J Med Internet Res 2010 Jun 14;12(2):e19 [FREE Full text] [doi: 10.2196/jmir.1549] [Medline: 20542858]

45. Barker KK. Electronic support groups, patient-consumers, and medicalization: the case of contested illness. J Health Soc Behav 2008 Mar 01;49(1):20-36. [doi: 10.1177/002214650804900103] [Medline: 18418983]

46. Huh J, Ackerman MS. Collaborative Help in Chronic Disease Management: Supporting Individualized Problems. CSCW 2012;2012:853-862 [FREE Full text] [doi: 10.1145/2145204.2145331] [Medline: 25360442]

47. Gui X, Chen Y, Kou Y, Pine K, Chen Y. Investigating Support Seeking from Peers for Pregnancy in Online Health Communities. Proc. ACM Hum.-Comput. Interact 2017 Dec 06;1(CSCW):1-19. [doi: 10.1145/3134685]

48. Alqassim M, Kresnye K, Siek K, Wolters M. Facebook for Support versus Facebook for Research: The Case of Miscarriage. In: Extended Abstracts of the 2019 CHI Conference on Human Factors in Computing Systems. USA: ACM; 2019 May Presented at: CHI Conference on Human Factors in Computing Systems; May, 2019; Glasgow Scotland Uk p. 1-6. [doi: $10.1145 / 3290607.3312772]$ 
49. Andalibi N. What Happens After Disclosing Stigmatized Experiences on Identified Social Media: Individual, Dyadic, and Social/Network Outcomes. In: Proceedings of the 2019 CHI Conference on Human Factors in Computing Systems. ACM Digital Library: ACM Press; 2019 May Presented at: CHI Conference on Human Factors in Computing Systems; May, 2019; Glasgow Scotland Uk p. 1-15 URL: https://dl.acm.org/doi/proceedings/10.1145/3290605 [doi: 10.1145/3290605.3300367]

50. D'Agostino AR, Optican AR, Sowles SJ, Krauss MJ, Escobar LK, Cavazos-Rehg PA. Social networking online to recover from opioid use disorder: A study of community interactions. Drug Alcohol Depend 2017 Dec 01;181:5-10. [doi: 10.1016/j.drugalcdep.2017.09.010] [Medline: 29024875]

51. Zhang M, Yang CC. Using content and network analysis to understand the social support exchange patterns and user behaviors of an online smoking cessation intervention program. J Assn Inf Sci Tec 2014 May 19;66(3):564-575. [doi: 10.1002/asi.23189]

52. Doherty K, Marcano-Belisario J, Cohn M, Mastellos N, Morrison C, Car J, et al. Engagement with Mental Health Screening on Mobile Devices: Results from an Antenatal Feasibility Study. In: Proceedings of the 2019 CHI Conference on Human Factors in Computing Systems. New York: ACM Press; 2019 May Presented at: CHI Conference on Human Factors in Computing Systems; May, 2019; Glasgow Scotland Uk p. 1-15 URL: https://dl.acm.org/doi/10.1145/3290605.3300416 [doi: $10.1145 / 3290605.3300416$ ]

53. MacLean D, Gupta S, Lembke A, Manning C, Heer J. Forum77: An Analysis of an Online Health Forum Dedicated to Addiction Recovery. In: Proceedings of the 18th ACM Conference on Computer Supported Cooperative Work \& Social Computing. Canada: ACM Press; 2015 Feb Presented at: Computer Supported Cooperative Work and Social Computing; March, 2015; Vancouver BC Canada p. 1511-1526. [doi: 10.1145/2675133.2675146]

54. Eysenbach G, Powell J, Kuss O, Sa E. Empirical studies assessing the quality of health information for consumers on the world wide web: a systematic review. JAMA 2002;287(20):2691-2700. [doi: 10.1001/jama.287.20.2691] [Medline: 12020305]

55. Silver MP. Patient perspectives on online health information and communication with doctors: a qualitative study of patients 50 years old and over. J Med Internet Res 2015;17(1):e19 [FREE Full text] [doi: 10.2196/jmir.3588] [Medline: 25586865]

56. Hanson CL, Cannon B, Burton S, Giraud-Carrier C. An exploration of social circles and prescription drug abuse through Twitter. J Med Internet Res 2013 Sep;15(9):e189 [FREE Full text] [doi: 10.2196/jmir.2741] [Medline: 24014109]

57. Timeline of Selected FDA Activities and Significant Events Addressing Opioid Misuse and Abuse Internet. U.S. Food \& Drug Administration. 2020. URL: https://www.fda.gov/media/126835/download [accessed 2021-01-05]

58. Gonzalez-Hernandez G. On the Ethics of Using Social Media Data for Health Research Internet. NLM Musings Mezzanine. 2019 Jun 25. URL: https://nlmdirector.nlm.nih.gov/2019/06/25/on-the-ethics-of-using-social-media-data-for-health-research/ [accessed 2019-09-11]

59. Barth S, de Jong MD. The privacy paradox - Investigating discrepancies between expressed privacy concerns and actual online behavior - A systematic literature review. Telematics and Informatics 2017 Nov;34(7):1038-1058. [doi:

10.1016/j.tele.2017.04.013]

60. Steinfeld N. "I agree to the terms and conditions": (How) do users read privacy policies online? An eye-tracking experiment. Computers in Human Behavior 2016 Feb;55:992-1000. [doi: 10.1016/j.chb.2015.09.038]

61. Liang OS, Sheffield JS, Taylor CO. Detecting Patterns of Prescription Drug Use During Pregnancy and Lactation with Visualization Techniques. In: AMIA Joint Summits on Translational Science proceedings. 2019 Presented at: AMIA Joint Summits on Translational Science; 2019 Mar 25; San Francisco, CA p. 478-487.

62. Braun V, Clarke V. Using thematic analysis in psychology. Qualitative Research in Psychology 2006 Jan;3(2):77-101. [doi: 10.1191/1478088706qp063oa]

63. Wolff B, Mahoney F, Lohiniva A, Corkum M. Collecting and Analyzing Qualitative Data. In: Oxford Scholarship Online. CDC Field Epidemiol Man Internet Oxford, New York: Oxford University Press; 2018.

64. Hasin DS, O'Brien CP, Auriacombe M, Borges G, Bucholz K, Budney A, et al. DSM-5 criteria for substance use disorders: recommendations and rationale. Am J Psychiatry 2013 Aug;170(8):834-851 [FREE Full text] [doi:

10.1176/appi.ajp.2013.12060782] [Medline: 23903334]

65. HHS Guide for Clinicians on the Appropriate Dosage Reduction or Discontinuation of Long-Term Opioid Analgesics. U.S. Department of Health and Human Services. 2019. URL: https://www.hhs.gov/opioids/sites/default/files/2019-10/

Dosage Reduction Discontinuation.pdf [accessed 2021-01-05]

66. Kummervold PE, Gammon D, Bergvik S, Johnsen JK, Hasvold T, Rosenvinge JH. Social support in a wired world: use of online mental health forums in Norway. Nord J Psychiatry 2002 Jul;56(1):59-65. [doi: 10.1080/08039480252803945] [Medline: 11869468$]$

67. Rubya S, Yarosh S. Video-Mediated Peer Support in an Online Community for Recovery from Substance Use Disorders. In: Proceedings of the 2017 ACM Conference on Computer Supported Cooperative Work and Social Computing. 2017 Feb Presented at: Computer Supported Cooperative Work and Social Computing; 2017 Feb 25; Portland Oregon USA p. 1454-1469. [doi: 10.1145/2998181.2998246]

68. Bandura, Albert. Self-Efficacy: The Exercise of Control. In: Encyclopedia of Psychological Assessment. Thousand Oaks, California, United States: SAGE Publications Ltd; 1997:978. 
69. Glanz K, Rimer B, Viswanath K. Health behavior and health education: Theory, Research, and Practice. In: Theory, Research, and Practice. 4th Edition. California: Jossey-Bass; 2008:978-0787996147.

70. Folkman S, Lazarus RS. The relationship between coping and emotion: implications for theory and research. Soc Sci Med 1988;26(3):309-317. [doi: 10.1016/0277-9536(88)90395-4] [Medline: 3279520]

71. Folkman S, Moskowitz JT. Positive affect and the other side of coping. American Psychologist 2000;55(6):647-654. [doi: 10.1037/0003-066x.55.6.647]

72. Practitioner and Program Data. Substance Abuse and Mental Health Services Administration. URL: https://www.samhsa.gov/ medication-assisted-treatment/practitioner-program-data/certified-practitioners [accessed 2021-01-05]

73. Patrick SW, Buntin MB, Martin PR, Scott TA, Dupont W, Richards M, et al. Barriers to accessing treatment for pregnant women with opioid use disorder in Appalachian states. Subst Abus 2019 Oct 09;40(3):356-362. [doi: 10.1080/08897077.2018.1488336] [Medline: 29949454]

74. Nesvåg S, McKay JR. Feasibility and Effects of Digital Interventions to Support People in Recovery From Substance Use Disorders: Systematic Review. J Med Internet Res 2018 Aug 23;20(8):e255 [FREE Full text] [doi: 10.2196/jmir.9873] [Medline: $\underline{30139724]}$

75. Kim SJ, Marsch LA, Brunette MF, Dallery J. Harnessing Facebook for Smoking Reduction and Cessation Interventions: Facebook User Engagement and Social Support Predict Smoking Reduction. J Med Internet Res 2017 May 23;19(5):e168 [FREE Full text] [doi: 10.2196/jmir.6681] [Medline: 28536096]

76. Rogers MA, Lemmen K, Kramer R, Mann J, Chopra V. Internet-Delivered Health Interventions That Work: Systematic Review of Meta-Analyses and Evaluation of Website Availability. J Med Internet Res 2017 Mar 24;19(3):e90 [FREE Full text] [doi: 10.2196/jmir.7111] [Medline: 28341617]

77. Crane D, Garnett C, Brown J, West R, Michie S. Behavior change techniques in popular alcohol reduction apps: content analysis. J Med Internet Res 2015 May 14;17(5):e118 [FREE Full text] [doi: 10.2196/jmir.4060] [Medline: 25977135]

78. Wiebe R, Griffin A, Zheng Y, Harris K, Cleveland H. Twelve Steps, Two Factors: Coping Strategies Moderate the Association Between Craving and Daily 12-Step Use in a College Recovery Community. Subst Use Misuse 2018;53(1):127. [doi: 10.1080/10826084.2017.1325904] [Medline: 28813187]

79. Mason M. Sample Size and Saturation in PhD Studies Using Qualitative Interviews. Forum Qual Sozialforschung Forum Qual Soc Res Internet 2010:24.

80. Green BM, Van Horn KT, Gupte K, Evans M, Hayes S, Bhowmick A. Assessment of Adaptive Engagement and Support Model for People With Chronic Health Conditions in Online Health Communities: Combined Content Analysis. J Med Internet Res 2020 Jul 07;22(7):e17338 [FREE Full text] [doi: 10.2196/17338] [Medline: 32492651]
Abbreviations
CPS: Child Protective Service
DATA: Drug Addiction Treatment Act
MAT: medication-assisted treatment
NAS: neonatal abstinence syndrome
OHC: online health community
OUD: opioid use disorder
SUD: substance use disorder

Edited by G Eysenbach; submitted 17.02.20; peer-reviewed by S Li, JP Allem; comments to author 26.10.20; revised version received
11.12.20; accepted 20.12.20; published 04.02.21
Please cite as:
Liang OS, Chen Y, Bennett DS, Yang CC
Identifying Self-Management Support Needs for Pregnant Women With Opioid Misuse in Online Health Communities: Mixed Methods
Analysis of Web Posts
J Med Internet Res 2021;23(2):e18296
URL: $\underline{\text { https://www.jmir.org/2021/2/e18296 }}$
doi: $10.2196 / 18296$
PMID: $\underline{3353895}$

(C) Ou Stella Liang, Yunan Chen, David S Bennett, Christopher C Yang. Originally published in the Journal of Medical Internet Research (http://www.jmir.org), 04.02.2021. This is an open-access article distributed under the terms of the Creative Commons Attribution License (https://creativecommons.org/licenses/by/4.0/), which permits unrestricted use, distribution, and reproduction in any medium, provided the original work, first published in the Journal of Medical Internet Research, is properly cited. The 
complete bibliographic information, a link to the original publication on http://www.jmir.org/, as well as this copyright and license information must be included. 